Original Research Article

\title{
Assessment of oxidative stress in breast cancer patients: a hospital based study
}

\author{
Jagruti Bhattacharjee $^{1}$, Sangita Jogdand ${ }^{1 *}$, R. K. Shinde ${ }^{2}$, Sourav Goswami ${ }^{3}$
}

\begin{abstract}
${ }^{1}$ Department of Pharmacology,
${ }^{2}$ Department of Surgery, J. N.

M. C. Sawangi (Meghe),

Wardha, Maharashtra, India

${ }^{3}$ Department of Community

medicine, M. G. I. M. S.

Sewagram, Maharashtra, India

Received: 12 March 2018

Accepted: 03 April 2018

*Correspondence to:

Dr. Sangita Jogdand,

Email: drsangitaraj@gmail.com
\end{abstract}

Copyright: (c) the author(s), publisher and licensee Medip Academy. This is an openaccess article distributed under the terms of the Creative Commons Attribution NonCommercial License, which permits unrestricted noncommercial use, distribution, and reproduction in any medium, provided the original work is properly cited.

\begin{abstract}
Background: Oxidative stress occurs as a result of the disturbance in the balance between the production of reactive oxygen species (free radicals) and antioxidant defenses. This is regarded as a possible etilogical factor in production of breast carcinoma, which is the most cmmon cancer among the females both globally as well as in India. Oxidative stress also plays an important role in progression of cancer breast. This study was conducted to compare the levels of superoxide dismutase (SOD) and malondialdehyde (MDA) in breast cancer patients and normal age matched female participants.

Methods: This study was conducted in AVBR Hospital, Sawangi (Meghe) among 30 female breast cancer patients admitted in the surgery ward for treatment after being diagnosed with the disease, who attended the hospital from July 2016 to June 2017. Breast cancer patients of stage I and II were included in the study. Patients suffering from any other diseases apart from breast cancer like diabetes, hypertension, thyroid illnesses and other sort of cancers are excluded from the study. For each of the study participant, age and sex matched controls were selected who were mostly the relatives of patients attending the hospital and were devoid of any illnesses. Venous blood sample was collected from all the patients as well as the controls that were used for determination of the levels of SOD (superoxide dismutase) and MDA (malondialdehyde). Written informed consent was taken from all the study participants before drawing the blood samples.
\end{abstract}

Results: Authors have measured the markers of oxidative stress in breast cancer patients after diagnosis of breast cancer and compared theses blood levels with those of the controls. The mean MDA $(\mathrm{nmol} / \mathrm{ml})$ levels for the breast cancer patients and the controls were 26.14 and 15.83 respectively, while the SOD ( $\mathrm{U} / \mathrm{gm} \mathrm{Hb}$ ) levels were 0.12 and 0.16 respectively and the difference of the mean were statistically significant ( $\mathrm{p}$ value $<0.01$ ).

Conclusions: There is presence of increased oxidative stress in breast cancer patients as compared to the healthy controls.

Keywords: Breast cancer, Malondialdehyde, Oxidative stress, Superoxide dismutase

\section{INTRODUCTION}

Breast cancer is the most common cancer among women in both the developed and the developing countries in the world with an estimated 1,671,149 new cancer cases diagnosed in 2012, which accounts for $25 \%$ of all the cancers. With an estimated 521,907 cases of deaths due to breast cancer occurring in the world (2012), breast cancer ranks first as the cause of death from overall cancers in the world. For the less developed countries, breast cancer is the most frequent cause of cancer death among the women. $^{1,2}$ The risk of breast cancer increases with early menarche, late menopause, late age for the first pregnancy, obesity, dense breast tissue, oral contraceptive use, 
hormone replacement therapy, addiction to alcohol and tobacco, positive family history. ${ }^{3}$ Apart from these, a number of genes, like BRCA1 and BRCA2, and p53 have been linked to breast cancer susceptibility and development. ${ }^{4}$

Etiology of breast cancer is multifactorial which includes genetic, environmental, social, demographic and hormonal factors. Evidences are there to prove the occurrence of the disease as a result of increased oxidative stress. ${ }^{3,5}$ Free radicals are the chemical species possessing an unpaired electron and are very reactive. They are produced in cells either as by-products of metabolism, or during phagocytosis in the extra-nuclear compartment by the mitochondrial respiratory chain and the mixed function oxidase system. These free radicals cause damage to the cellular structure like lips, proteins and nucleic acids leading to severe abnormalities. ${ }^{6,7}$

Antioxidants are compounds that react with free radicals either in vivo or in vitro and prevent oxidative damage. Endogenous antioxidant defenses are both enzymatic such as the superoxide dismutase, glutathione peroxidases, glutathione reductase and catalase; while non-enzymatic antioxidants namely vitamin $\mathrm{C}$, vitamin $\mathrm{E}$ and vitamin $\mathrm{A}$ which play a main role in protecting the body against the harmful effects of free radicals and prevents excessive oxidative damage. Exogenous antioxidants are mostly the nutritional antioxidants that directly neutralize the free radicals, reduce the peroxide concentrations and repair oxidized membranes and ultimately decrease the production of reactive oxygen species via lipid metabolism. ${ }^{8}$ Under normal circumstances, there is a steady state between the oxidants and the antioxidants inside the human body. Oxidative stress is a process which occurs due to a disturbance in the balance between the production of a reactive oxygen species (ROS) or free radicals (singlet oxygen, superoxide anions, hydrogen peroxide and hydroxyl radical) and the efficiency of the antioxidant defense systems like glutathione and enzymes such as superoxide dismutase (CuZn-SOD, Mn-SOD), catalase (CAT), glutathione peroxidase (GPx), glutathione reductase (GRx) and glutathione-S-transferase (GST). ${ }^{9}$ The oxidative damage to both the nuclear DNA and the mitochondrial DNA may lead to mutations that activate oncogenes or inactivate tumor suppressor genes. ${ }^{10}$ Amin $\mathrm{KA}$ et al, have reported the involvement of ROS in etiology and development of breast cancer.

They have studied the effect of breast cancer on the level of various enzymes with antioxidant activities and biomarkers for oxidative stress and found an increased NO and lipid peroxidation in the patients of breast cancer with decreased antioxidant effects of catalase and reduced glutathione (GSH). This occurred as a result of free radical generation, which resulted in damage at cellular level. Similar observations were also found in the studies conducted by Kasapovic et al, and Prabasheela et al, where the blood levels of catalase and superoxide dismutase were found to decrease that indicated increased activity of the free radicals in the breast cancer patients and decreased level of antioxidants as they are utilized for quenching free radicals. ${ }^{4,11,12}$

This study was thus undertaken to assess and compare the oxidative stress in breast cancer patients with age and sex matched controls. Aim was to assess the oxidative stress in breast cancer patients and to compare it with that of healthy controls.

\section{METHODS}

It was observational study.

\section{Locus of study}

The present study was carried out in the department of surgery, Acharya Vinoba Bhave Rural Hospital of Jawaharlal Nehru Medical College. All the biochemical procedures were carried out in Central research laboratory, DMIMS (DU), Sawangi (Meghe), Wardha.

\section{Study subjects}

\section{Study group}

Thirty patients of carcinoma breast of operable stages (stage I and Stage II) of all the age groups attending the surgery department for treatment from 15th October 2015 to September 2017 were included in the present study.

\section{Control group}

Thirty age and sex matched healthy volunteers were enrolled as controls. Written informed consent was taken from all the study participants.

\section{Inclusion criteria}

Diagnosed cases of female breast cancer patients coming for treatment who consented were included. We have taken only Stage I and Stage II breast cancer in our study as we were interested to see the change in oxidative stress among the early breast cancer patients.

\section{Exclusion criteria}

Patients of cancer breast with associated chronic illness such as diseases altering antioxidant levels in healthy and cancer patients (like diabetes, hypertension, myocardial diseases, renal diseases, pancreatic diseases, pulmonary diseases, on hormone therapy and pregnancy) and patients with fibro adenoma breast or any previous treatment for breast carcinoma were excluded from this study. Patients who did not give written informed consent.

\section{Methodology}

- Venous blood sample was collected from the breast cancer patients of stage I and II fulfilling our 
inclusion criteria at diagnosis, and oxidative stress (Superoxide dismutase (SOD) and Malondialdehyde (MDA)) was measured.

- Blood samples were collected from the 30 healthy female controls for measuring the level of MDA and SOD.

- MDA level was measured by thiobarbituric acid (TBA) method and SOD level was measured by inhibition of autooxidation of Pyrogallol (Marklund M).

\section{RESULTS}

The mean age of the breast cancer patients was $52.53 \pm 9.43$ years and those of the control group was 53.97 \pm 10.06 years respectively. There was no statistically significant difference in between the mean ages of control and study group. We have measured the markers of oxidative stress in breast cancer patients after diagnosis of breast cancer and compared theses blood levels with those of the controls. The MDA (nmol/ml) levels for the breast cancer patients and the controls were 26.14 and 15.83 respectively (Figure 1), while the SOD (U/gm Hb) levels were 0.12 and 0.16 respectively (Figure 2 ). The difference of the mean between the MDA and Sod levels of the breast cancer patients and the controls are found to be statistically significant (p value $<0.01$ ).

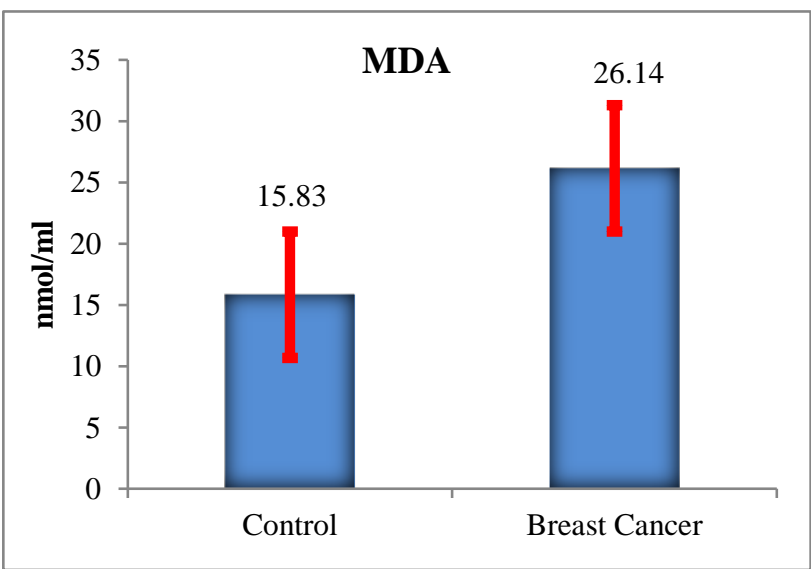

Figure 1: Levels of MDA in the blood of breast cancer patients and control representing healthy subjects. values represent the mean \pm SEM.

Authors have taken cases of early breast cancer in our study to see the changes in the oxidative stress occurring in hem as compared to the healthy controls. Figure 3 shows the comparison of the MDA levels among stage I and stage II of breast cancer as compared to controls, where we found the mean MDA values are 26.32, 27.91 and $15.83 \mathrm{nmol} / \mathrm{ml}$ respectively. The levels of MDA are increasing as the stage of breast cancer increases, but this difference was not found to be statistically significant ( $p$ value $>0.05$ ).

Similarly, Figure 4 shows the comparison of the SOD levels among stage I and stage II of breast cancer as compared to controls, where we found the mean SOD values are $0.12,0.11$ and $0.16 \mathrm{U} / \mathrm{gm} \mathrm{Hb}$ respectively. These levels of SOD are decreasing as the stage of disease increases, and this difference was found to be significant statistically ( $\mathrm{p}$ value $<0.05$ ).

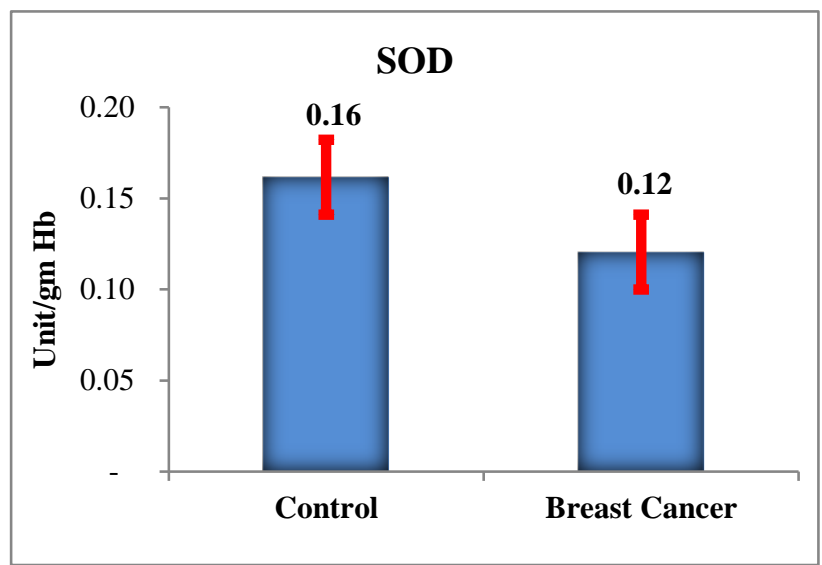

Figure 2: Levels of SOD in the blood of breast cancer patients and control representing healthy subjects. Values represent the mean \pm SEM.

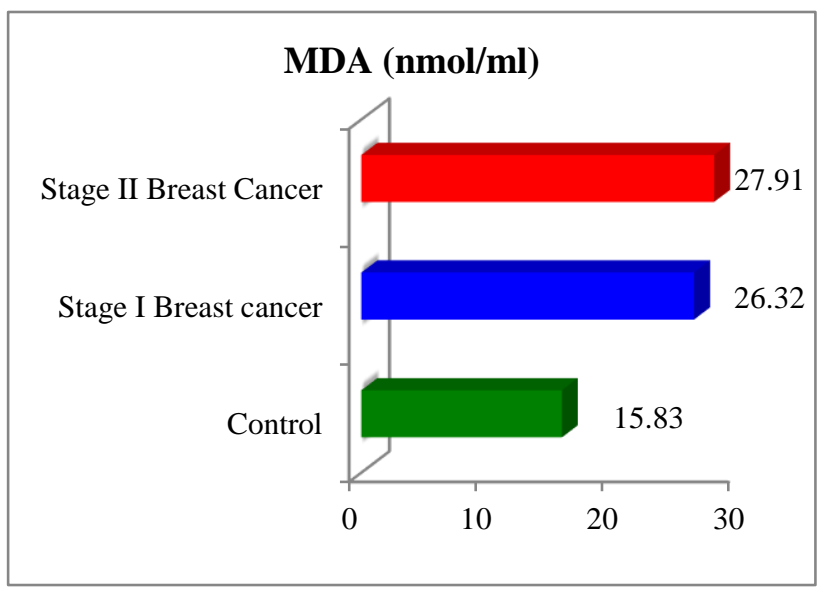

Figure 3: MDA (nmol/ml) level in the early breast cancer as compared to control.

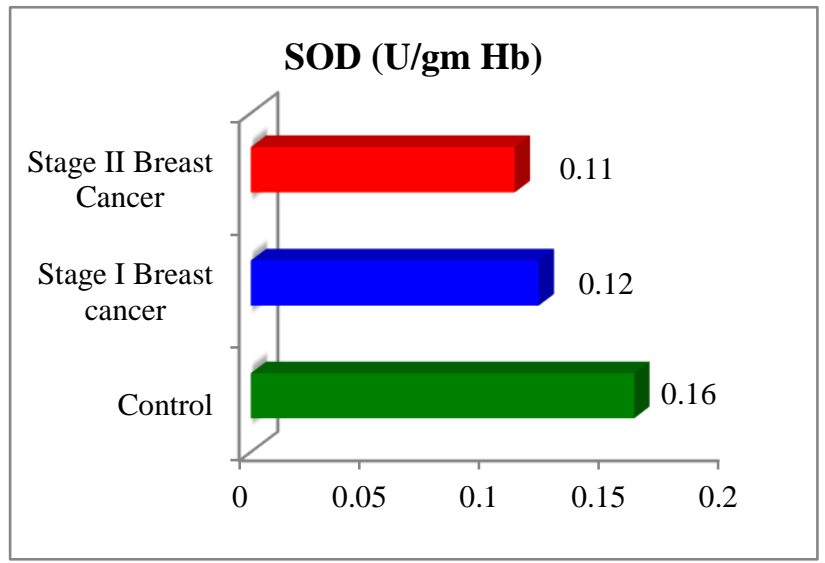

Figure 4: SOD (U/gm Hb) level in the early breast cancer as compared to control. 


\section{DISCUSSION}

Oxidative stress produced through either increased free radical generation and/or a decreased antioxidant level in the target cells and tissues has been suggested to play an important role in carcinogenesis. It has been found that the reactive oxygen species are involved in initiation and promotion of cancer. ${ }^{14,15}$

In our study to compare oxidative stress in carcinoma breast patients we have included 30 healthy age matched females in control group (mean age 53.97 years) and 30 patients of carcinoma breast of which stage I patients were $57 \%$ and stage II patients were $43 \%$. Mean age of study group was 52.53 years. In the current research, we studied both the MDA and SOD levels in the blood of breast cancer patients at diagnosis of breast cancer, we have estimated the SOD and MDA level in normal subjects.

In this study, we found that MDA levels were elevated in the serum of patients with breast cancer. As far as breast cancer is concerned, enhanced oxidative stress in tissues and serum has previously been reported. Some authors have demonstrated increased lipid peroxidation and increased MDA-DNA adducts have been detected in mammary tissues of breast cancer patients. ${ }^{16,17}$

In the study, conducted by Kumaraguruparan $\mathrm{R}$ et al, and Portakal $\mathrm{O}$ et al, 66 found that the MDA levels were significantly raised in the breast cancer patients. ${ }^{18,19}$ Hristozov D et al, also came up with a similar finding, where the MDA levels increased significantly among the cancer patients when compared with the control. ${ }^{20} \mathrm{~A}$ way of analyzing the oxidative stress is by quantification of the lipid peroxidation by measuring the different biomarkers of oxidative stress like MDA or Malondialdehyde, which is a low molecular weight aldehyde, which is produced as a result of the lipid peroxidation in the aerobic organisms that is generated through several enzymatic and nonenzymatic reactions. ${ }^{19}$

The mean level of antioxidant SOD in the controls was $0.16 \mathrm{Unit} / \mathrm{gm} \mathrm{Hb}$ and the breast cancer patients at the time of diagnosis was $0.12 \mathrm{Unit} / \mathrm{gm} \mathrm{Hb}$ in the present study and this reduction in SOD may be related to carcinoma breast induced oxidative stress. This difference of mean is also significant statistically ( $\mathrm{p}$ value $<0.01$ ), similar results of reduced level of SOD was observed by Hristozov D et al, who compared the SOD level in cancer patients at different stages with the control and benign disease. Though they did not find any significant difference between the benign disease and the control group, but the SOD levels decreased significantly in all the stages of carcinoma breast when compared with the normal individual. ${ }^{20}$

Super oxide dismutase (SOD) is an enzyme that helps in catalyzing the potentially harmful superoxide radical $\left(\mathrm{O}^{2}\right)$ in the cells that prevents tissue damage. ${ }^{21,22}$ Under the conditions of oxidative stress, as in cases of breast cancer, increased concentration of reactive oxygen species initiates damage to many biomolecules, catalysis of these harmful radical by SOD leads to decreased levels of this protective antioxidant. $^{23}$

The knowledge of significantly increased oxidative stress in the breast cancer patients as compared to the healthy individual that we have gathered from the present study may be utilized in developing strategies for preventive and curative aspects of breast cancer.

\section{CONCLUSION}

Our study concluded that the oxidative stress in patients of carcinoma breast is increased as compared to healthy controls as evidenced by increased malondialdehyde (MDA) and decreased levels of superoxide dismutase (SOD) in breast cancer patients.

Funding: No funding sources

Conflict of interest: None declared

Ethical approval: The study was approved by the Institutional Ethics Committee

\section{REFERENCES}

1. Ferlay J, Soerjomataram I, Dikshit R, Eser S, Mathers C, Rebelo M, et al. Cancer incidence and mortality worldwide: sources, methods and major patterns in GLOBOCAN 2012. Inter J Cancer. 2015;136(5).

2. Peto J. Cancer epidemiology in the last century and the next decade. Nature. 2001;411:390-5.

3. Rockenbach G, Di Pietro PF, Ambrosi C, Boaventura BC, Vieira FG, Crippa CG, et al. Dietary intake and oxidative stress in breast cancer: before and after treatments. Nutricion hospitalaria. 2011;26(4).

4. Amin KA, Mohamed BA, Mohamed A M, Ibrahem SO. Impact of Breast Cancer and Combination Chemotherapy on Oxidative Stress, Hepatic and Cardiac Markers. J Breast Cancer. 2012;15(3):306-12.

5. Singh G, Maulik SK, Jaiswal A, Kumar P, Parshad R. Effect on antioxidant levels in patients of breast carcinoma during neoadjuvant chemotherapy and mastectomy. MJMS. 2010;17(2):24.

6. Singh S, Brocker C, Koppaka V, Chen Y, Jackson BC, Matsumoto A, Thompson DC, Vasiliou V. Aldehyde dehydrogenases in cellular responses to oxidative/electrophilic stress. Free Radic Biol Med. 2013;56:89-101.

7. Lobo V, Patil A, Phatak A, Chandra N. Free radicals, antioxidants and functional foods: Impact on human health. Pharmacogn Rev. 2010;4(8):118-26.

8. Nimse S B, Pal D. Free radicals, natural antioxidants and their reaction mechanisms. RSC Adv. 2015;5:27986-28006.

9. Yoshikawa T, Naito Y. What is oxidative stress? JMAJ. 2002:45(7):271-76.

10. Weijl NI, Hopman,GD, Wipkink BE, Lentjes M, Berger HM, Cleton FJ, et al. Cisplatin combination chemotherapy induces a fall in plasma antioxidants of cancer patients. Annals Oncology. 1998;9:1331-37. 
11. Kasapović J, Pejić S, Stojiljković V, Todorović A, Radošević-Jelić L, Saičić ZS, et al. Antioxidant status and lipid peroxidation in the blood of breast cancer patients of different ages after chemotherapy with 5fluorouracil, doxorubicin and cyclophosphamide. Clin Biochem. 2010;43(16-17):1287-93.

12. Prabasheela B, Singh AK, Fathima A, Pragullbh K, Deka NJ, Kumar R. Association between Antioxidant Enzymes and Breast Cancer. Recent Res Sci Technology. 2011;3(11):93-5.

13. Marklund S, Marklund G. Involvement of the superoxide anion radical in the autoxidation of pyrogallol and a convenient assay for superoxide dismutase. Eur J Biochem. 1974;47(3):469-74.

14. Trush MA, Kensler TW. An overview of the relationship between oxidative stress and chemical carcinogenesis. Free Radic Biol Med. 1991;10:201-9.

15. Rice-Evans C, Burdon R. Free radical-lipid interactions and their pathological consequences. Prog Lipid Res. 1993;32:71-110.

16. Wang M, Dhingra K, Hittelman WN, Liehr JG, De Andrade M, Li D. Lipid peroxidation-induced putative malondialdehyde-DNA adducts in human breast tissues. Cancer Epidemiology Prevention Biomarkers. 1996;5(9):705-10.

17. Boyd NF, McGuire V. The possible role of lipid peroxidation in breast cancer risk. Free Radic Biol Med. 1991;10:185-90.
18. Kumaraguruparan R, Subapriya R, Viswanathan P, Nagini S. Tissue lipid peroxidation and antioxidant status in patients with adenocarcinoma of the breast. Clin Chim Acta. 2002;325:165-70.

19. Portakal O, Ozkaya O, Erden Inal M, Bozan B, Kosan M, Sayek I. Coenzyme Q10 concentrations and antioxidant status in tissues of breast cancer patients. Clin Biochem. 2000;33:279-84

20. Hristozov D, Gadjeva V, Vlaykova T, Dimitrov G. Evaluation of oxidative stress in patients with cancer. Arch Physiol Biochem. 2001;109(4):331-6.

21. Goodman L, Gilman A, Brunton L. Goodman and Gilman's manual of pharmacology and therapeutics. 12th ed. New York: McGraw-Hill Medical;2011.

22. Katzung BG, Masters SB, Trevor AJ, editors. Basic \& clinical pharmacology. $12^{\text {th }}$ ed. New York; New Delhi: Tata McGraw-Hill education;2012.

23. WHO. Breast cancer: prevention and control. 2015. Available at: http://www.who.int/cancer/detection/ breastcancer/en/index1.html\#cited:10.08.16.

Cite this article as: Bhattacharjee $\mathrm{J}$, Jogdand $\mathrm{S}$, Shinde RK, Goswami S. Assessment of oxidative stress in breast cancer patients: a hospital based study. Int J Basic Clin Pharmacol 2018;7:966-70. 